\title{
Modeling and Control for Emission Management in Hybrid Electric Commercial Vehicles
}

Olov Holmer

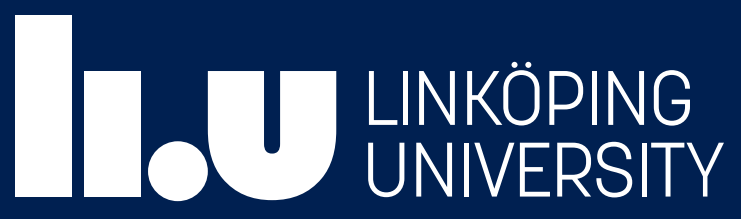





\title{
Modeling and Control for Emission Management in Hybrid Electric Commercial Vehicles
}

\author{
Olov Holmer
}

1 LINKÖPING UNIVERSITY

Division of Vehicular Systems Department of Electrical Engineering Linköping University

SE-581 83 Linköping, Sweden

Linköping 2022 
Linköping Studies in Science and Technology

Dissertations No. 2204

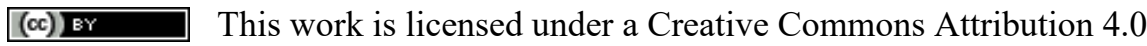
International License.

https://creativecommons.org/licenses/by/4.0/

Olov Holmer

olov.holmereliu.se

www.vehicular.isy.liu.se

Division of Vehicular Systems

Department of Electrical Engineering

Linköping University

SE-581 83 Linköping, Sweden

Copyright $\odot 2022$ Olov Holmer, unless otherwise noted.

Published articles have been reprinted with permission from the respective copyright holder.

Holmer, Olov

Modeling and Control for Emission Management in Hybrid Electric

Commercial Vehicles

ISBN 978-91-7929-191-4 (print)

ISBN 978-91-7929-192-1 (PDF)

ISSN 0345-7524

DOI https://doi.org/10.3384/9789179291921

Typeset using $\mathrm{LAT}_{\mathrm{E}} \mathrm{X} 2 \varepsilon$

Printed by LiU-Tryck, Linköping, Sweden 2022 




\section{Populärvetenskaplig sammanfattning}

Elhybridfordon är attraktiva lösningar för att uppfylla nuvarande och kommande strikta lagstiftning på bränsleförbrukning och emissioner. Flertalet studier har kunnat visa på lägre bränsleförbrukning från elhybridfordon jämfört med konventionella fordon. Studier har även kunnat visa på mindre mängd av övriga emissioner från elhybridfordon, men detta är ett betydligt mindre undersökt område. Framför allt så är effekten av de längre perioder med förbränningsmotorn avstängd, som ofta uppstår när elhybridfordon används, ett relativt outforskat område vilket denna avhandling ämnar adressera, med fokus på avvägningen mellan bränsleförbrukning och utsläpp av kväveoxider $\left(\mathrm{NO}_{\mathrm{x}}\right)$.

Moderna drivlinor är komplexa system vilket måste tas hänsyn till när dess reglersystem utvecklas, detta är inte minst sant för elhybriddrivlinor. För detta har modellbaserad reglering visat sig vara ett utmärkt verktyg. En grundförutsättning för modellbaserad reglering är en modell av systemet, och i denna avhandling utvecklas därför en komponentbaserad modell av en fullständig elhybriddrivlina. Den komponentbaserade strukturen möjliggör att fokus kan läggas på att välja rätt modell för respektive komponent, med ytterligare fokus på de viktigaste komponenterna. Utöver den fullständiga modellen innehåller därför avhandlingen bidrag i form av modeller av de komponenter som anses viktigast. För att kunna göra avvägningar mellan bränsleförbrukning och emissioner identifieras motorns efterbehandlingssystemet som den viktigaste komponenten. När det kommer till $\mathrm{NO}_{\mathrm{x}}$ och tunga fordon så är efterbehandlingens uppgift att reducera NOx med hjälp av Selektiv Katalytisk Reduktion (SCR). För att kunna beskriva efterbehandlingssystemets beteende i scenarion med längre perioder med förbränningsmotorn avstängd så visas det att en modell som tar hänsyn till hur mycket ammoniak som finns lagrat i SCR-katalysatorn och att temperaturen i efterbehandlingssystemet inte är homogent fördelad utan varierar både $\mathrm{i}$ längdled och radiell led i de olika komponenterna behövs.

Den utvecklade modellen används för att utvecklas en reglerstrategi som hanterar avvägningen mellan bränsleförbrukning och $\mathrm{NO}_{\mathrm{x}}$ i scenarion med längre perioder med förbränningsmotorn avstängd. Strategin bygger på att värma efterbehandlingssystemet innan motorn stängs med avsikten att dess temperatur ska vara högre när motorn återigen startas. Det visas att denna strategi kan vara ett effektivt sätt att reducera $\mathrm{NO}_{x}$ i scenarion med motoravstängningar på upp till ett par timmar långa. I avhandlingen presenteras även reglerstrategier för andra relaterade problem. 



\section{Abstract}

Electrification of powertrains is a major trend in the vehicle industry. The reason behind this is mainly that electrification of a powertrain generally results in better fuel economy, by eliminating inefficient, low load, operation of the engine. This can be done in two ways: load shifting to shift the operation point of the engine to a more efficient one, or by turning off the engine completely. When it comes to emissions, load shifting generally have positive effect since it usually result in higher exhaust temperatures which are beneficial for the aftertreatment system. The effect from turning off the engine completely is more complicated. When the engine is turned off the aftertreatment system will start to cool down and will eventually lose its effectiveness, resulting in higher emissions when the engine is restarted. So-called green zones, zones established by legislation or demand of costumers, where the use of combustion engines is prohibited, are a good example of where this can be expected and is therefore a focus of this thesis. The applications are not limited to hybrids but also useful for all vehicles that make stops, e.g., commercial vehicles that make regulated 45 minutes breaks and loading/off-loading cargo.

A model of a complete hybrid electric heavy-duty vehicle is developed and validated. The model is a compilation of several submodels of the different components in the vehicle. To correctly estimate the pollutive emissions, the components in the aftertreatment system are the most important components and emphasis is put on how the concentrations in them are calculated. It is shown that a quasi-static model for the concentrations gives the best balance in terms of accuracy and simulation time for the application. The aftertreatment system submodels are validated against data from a high-fidelity model and the complete powertrain is validated against experimental data from a powertrain in a test stand, all with satisfactory results. The model is used to create a virtual environment where the effect different control strategies have on the emissions around green zones can be studied and optimized.

A control strategy based on pre-heating of the aftertreatment system is developed. The strategy heats the aftertreatment before turning off the engine in an optimal way to reduce $\mathrm{NO}_{\mathrm{x}}$. This strategy is shown to be effective for engine-off times up to a few hours. However, for longer engine-off times, pre-heating of the aftertreatment system induces a limitation on the amount of stored ammonia, making the strategy ineffective or even bad. The strategy is extended to handle scenarios with multiple engine-off events using an algorithm that finds the engine-off events and handle them separately, but with a common equivalence factor between fuel and $\mathrm{NO}_{\mathrm{x}}$ to link them. The strategy is shown to handle scenarios with multiple engine-off events well, and the resulting distribution of fuel between the events is close to optimal. 
Using a quasi-static engine model and by assuming instantaneous equilibrium between the gas and substrate temperatures in the aftertreatment system a simplified model with analytical solutions is developed. Using this model, numerical optimal control is used to calculate the optimal way of heating the aftertreatment system above a specific minimum temperature. The results show a two-phase behavior starting with a heating phase, where the front of the aftertreatment system is heated, followed by a blowing phase where the heat is distributed in the aftertreatment system. This stresses the importance of considering both temperature and mass flow and for this a concept called heating enthalpy is introduced. 


\section{Acknowledgments}

First of all I would like to thank my supervisor Lars Erisson for giving me the opportunity of pursuing a PhD degree and all the help along the way. The path has not always been straight, and I thank him for helping me find it, but also for allowing me to find it myself. Frank Willems and Fredrik Blomgren are acknowledged for valuable discussions and their expert knowledge of the field. Erik Frisk and Jan Åslund is acknowledged for all the discussions over the years, Erik for research in general and Jan for mathematics-related topics.

I would also like to thank everyone at the Division of Vehicular Systems for providing a great working environment, and for all the fika room discussions. A special thanks go to Kristoffer Ekberg, Robin Holmbom, and Viktor Leek for everything during these years; great food, office decorations, and training are just a few of the happy memories.

Finally, I want to thank my family. I am very grateful to my parents Lisa and Glen, and my sisters Erika and Karin. Without you I would never have gotten this far. And thank you, Angela, for all the support and encouragement. I am very lucky to have you in my life.

Linköping, January 2022

Olov Holmer 



\section{Contents}

1 Introduction 1

1.1 Background . . . . . . . . . . . . . . 1

1.2 Related Research . . . . . . . . . . . . . . . . . . . 2

1.3 Thesis Focus and Motivation $\ldots \ldots \ldots 2$

2 Publications and Contributions 5

2.1 Summary of the papers . . . . . . . . . . . . . 5

2.2 Scientific Contributions . . . . . . . . . . . . 11

$\begin{array}{ll}\text { References } & 13\end{array}$

$\begin{array}{lr}\text { Papers } & 15\end{array}$

I A Mean Value Model for Unsteady Gas Flows and Heat Trans$\begin{array}{ll}\text { fer in Pipes } & 17\end{array}$

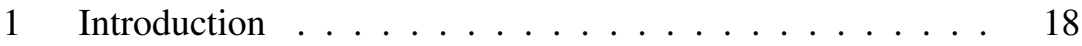

2 Heat Transfer in Pipes . . . . . . . . . . . . . . . . . 19

3 One-Dimensional Model . . . . . . . . . . . . . . . 20

4 Mean Value Model . . . . . . . . . . . . . . . . . . 23

5 Validation and Comparison . . . . . . . . . . . . 25

6 Conclusions . . . . . . . . . . . . . . . . . 29

References.................... . . 30

II Selective Catalytic Reduction Catalyst Modeling for Control Purposes 33

1 Introduction . . . . . . . . . . . . . . 34

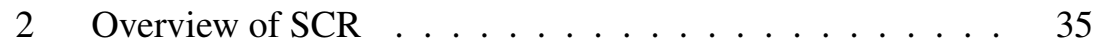

3 Foundation From Physics . . . . . . . . . . . . . . . . 39

4 Spatial Discretization . . . . . . . . . . . . . . 41

5 Analysis of Steady State Solutions _ . . . . . . . . . . 47

6 Temporal Discretization . . . . . . . . . . . . . . . . 49

7 Model Generation Tool . . . . . . . . . . . . . . . . 50 
8 Parameterization and Validation ............. 51

9 Results .................. 53

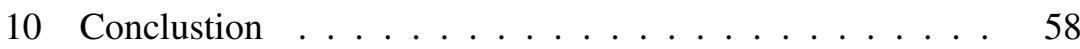

11 Discussion ................. 60

References .................. 61

A Matlab Example Code .............. 62

III A Simplified Diesel Particulate Filter Model 67

1 Introduction . . . . . . . . . . . . . 68

2 A Simple Example: A Flow-Through Channel . . . . . . . 70

3 Simplified Physical Description of a DPF . . . . . . . . 73

4 Implementation . . . . . . . . . . . . . . . 80

5 Parameter Estimation . . . . . . . . . . . . . . . 84

6 Results . . . . . . . . . . . . . . . . 85

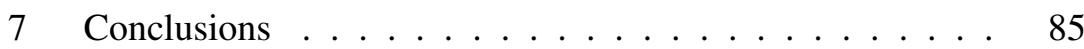

References . . . . . . . . . . . . . . . . . 86

IV Modeling of Engine Aftertreatment System Cooling for $\mathrm{Hy}-$ $\begin{array}{lr}\text { brid Vehicles } & 89\end{array}$

1 Introduction . . . . . . . . . . . . . . . . 90

2 Experimental Setup . . . . . . . . . . . . . . . . 92

3 After Treatment System Model . . . . . . . . . . . . . . 95

4 Silencer Model . . . . . . . . . . . . . . . . . . . . . . . 95

5 Pipe Model . . . . . . . . . . . . . . . . . . . . 95

6 Catalyst Model . . . . . . . . . . . . . . . . . . . . . . . 97

7 Parameterization . . . . . . . . . . . . . . . 102

8 Validation . . . . . . . . . . . . . . . . 102

9 Future Work . . . . . . . . . . . . . . . . . . 105

10 Conclusions . . . . . . . . . . . . . . 105

References . . . . . . . . . . . . . . . . 106

A Nomenclature . . . . . . . . . . . . . . . . . 107

B Taylor Expansion in Radial Dimension . . . . . . . . . . 108

C Higher Order Finite Differentiations in Discretization . . . 110

D Converging Gas and Substrate Temperature Derivation . . . 111

E Finite Differences . . . . . . . . . . . . . . . . . 112

V Modeling and Simulation of a Heavy-Duty Hybrid Electric Powertrain 113

1 Introduction . . . . . . . . . . . . . . . . . 114

2 Modeling . . . . . . . . . . . . . . . 115

3 Temporal Discretization . . . . . . . . . . . . . . . . 127

4 Results . . . . . . . . . . . . . . . . . . 131 
5 Conclusions . . . . . . . . . . . . . . . . . . 139

References . . . . . . . . . . . . . . . . . . . . . . 139

A Modeled Reactions in Aftertreatment System . . . . . . . . 142

VI Simultaneous Reduction of Fuel Consumption and $\mathrm{NO}_{\mathrm{x}}$ Emissions through Hybridization of a Long Haulage Truck 143

1 Introduction . . . . . . . . . . . . . . . . . . . 144

2 Vehicle Model . . . . . . . . . . . . . . . . . . . . 145

3 Controller . . . . . . . . . . . . . . . . . . . . . . 148

4 Simulation Results . . . . . . . . . . . . . . . . . . . . 151

5 Conclusion .................. 156

References . . . . . . . . . . . . . . . . 156

VII Modeling and Analytical Solutions for Optimal Heating of Aftertreatment Systems 159

1 Introduction . . . . . . . . . . . . . . . . . . 160

2 Model . . . . . . . . . . . . . . . . . . 161

3 Optimization Problem . . . . . . . . . . . . . . . . . . . 167

4 Results . . . . . . . . . . . . . . . . . . . . . . . . . 169

5 Future Work . . . . . . . . . . . . . . . . . . . . 175

6 Conclusions . . . . . . . . . . . . . . . 175

References . . . . . . . . . . . . . . . . . . . . 175

VIII Optimal Aftertreatment Pre-Heat Strategy for Minimum Tailpipe $\mathrm{NO}_{x}$ Around Green Zones 179

1 Introduction . . . . . . . . . . . . . . . . . 180

2 Modeling ...................... 182

3 Scenario . . . . . . . . . . . . . . . . . . . . . . 187

4 Thermal Management Strategy _... . . . . . . . . . . . . 190

5 Simulation results . . . . . . . . . . . . . . . . 193

6 Conclusions . . . . . . . . . . . . . . . . . . 197

References . . . . . . . . . . . . . . . . . . . . . . . . 197

A Reactions .................... 202

IX Predictive Emission Management Based on Pre-Heating for Heavy-Duty Powertrains 205

1 Introduction . . . . . . . . . . . . . 206

2 Modeling . . . . . . . . . . . . . . . . . 207

3 Emission Management Strategy . . . . . . . . . . . . . . 210

4 Results . . . . . . . . . . . . . . . . . 216

5 Conclusions .................... 223

References . . . . . . . . . . . . . . . 225 



\section{Chapter 1}

\section{Introduction}

Hybrid electric vehicles are attractive solutions to meet the demand of more fuel-efficient vehicles. Particularly attractive properties off hybrid electric vehicles are that they can offer a reduction in both fuel consumption and pollutant emissions, and offer the opportunity of full electric driving with zero local emissions. However, hybridization adds complexity to an already complex system and therefore, to fully utilize all the potential of hybrid electric vehicles, structured methods are needed.

\subsection{Background}

During the last decade, increasingly strict legislation on emissions have been introduced. In Europe, Euro VI legislation currently applies for heavy-duty onroad applications. Besides test cycles under laboratory conditions, this also sets in-service conformity targets for pollutant emissions, including nitrogen oxides $\left(\mathrm{NO}_{\mathrm{x}}\right)$, under real-world operation, see e.g. [1] for details. To support the European Union's greenhouse gas emission reductions target for 2030 of at least $50 \%$ compared to the 1990 levels, and net-zero emission of greenhouse gases by 2050 [2], combined with the zero-pollution vision for 2050 [3], coming legislation can be expected to be significantly stricter. One considered option is a comprehensive revision of the Euro VI legislation by introducing real-world emission monitoring and the possibility of automatically enabling a zero-emission mode depending on the location of a vehicle, so called "geofencing" or "green zones" [4]. This supports local and regional policy on low and zero emission zones; see e.g., [5] for an overview of activities in Europe and [6] for a harbor application. 


\subsection{Related Research}

The problem of energy management in a hybrid vehicle is a well studied topic that has been the focus of extensive research during the last decades and is well summarized in [7]. These methods can utilize simple models, usually the models only contain a state for the battery state of charge and the rest is described using static relations, as for example in the standard method Equivalent Consumption Minimization Strategy (ECMS), first proposed in [8] and [9].

Emission management in hybrid vehicles is a less well-studied topic, with only a limited number of publications, see [10] for a short summary of the field. In this context, the temperature of the aftertreament system is a dominating factor, and in [11] the ECMS is extended with a costate related to this temperature. However, this costate is not constant and must be chosen carefully for reliable behavior. Another thing to consider is that measures taken by the emission management system usually does not only affect the instantaneous emissions, but also future ones. Therefore, predictive methods like MPC are attractive solutions, and have successfully been implemented [10, 12, 13]. In these publications the aftertreament system is modeled using less detailed models, however, when prolonged engine-off events are considered the requirements on the model change [14], and a more detailed model can be beneficial [15].

In the open literature, green zone related research is dedicated to energy management for hybrid electric vehicles, see e.g. [16, 17], and the impact on pollutant emissions is not considered in these studies. This is in line with the identified control challenges for hybrid electric vehicles in [18]. However, a few related studies are found. In [19] the cold-start behavior of a parallel hybrid electric powertrain, which consists of a gasoline engine with a three-way catalyst, during an FTP urban cycle. [20] followed an integrated energy and emission management approach for a hybrid electric vehicle with an SCR system, and studied the powertrain behavior during a city cycle, which is characterized by short engine-off times. In summary, a detailed study on emission management strategies for improved emission behavior is missing. This especially holds for green zone scenarios.

\subsection{Thesis Focus and Motivation}

The main focus of this thesis is emission management for hybrid electric vehicles, especially considering the case of prolonged periods with the engine turned off. The development goes in a direction of adding more components, that solves the problems that arise from the introduction of new legislations. This is a process that makes the system more flexible and controllable, but also more complex to control. One way to handle the complexity in engineering is to 
use model-based methods to systematize and support the development. Another element that aids the engineer is optimization, which can utilize models to make intelligent choices for control inputs.

To support a systematic development of the control system for fuel consumption optimized hybrid vehicles that fulfill the emission legislations, a componentbased approach to the modeling is used. The component-based approach enables reuse and extensions of models when needed. This gives flexibility to the model and makes it possible to use existing models of components. The main problem is to find or develop suitable component-models and compile them into a complete system model.

The control problem that is studied in the thesis considers the trade-off between fuel consumption and $\mathrm{NO}_{\mathrm{x}}$ emissions, and especially how it is affected by the cooldown of the aftertreatment system when the engine is turned off in a hybrid electric vehicle, where it is possible to have all-electric propulsion. The complexity of the problem is high and there is a need for structured methods to handle all options and utilize all the potential of the system. Here, optimizationbased methods are proposed and used to find the solutions. In addition to the methods, the focus is also on drawing conclusions based on the results from applying the methods on specific problems. 



\section{Chapter 2}

\section{Publications and Contributions}

The thesis contributes with new knowledge about how the complete system, of diesel engine and aftertreatment system with selective catalytic reduction using urea injection, can be modelled, and controlled in a hybrid electric commercial vehicle. One part is the independent summary, review, extension, and implementation of models for the system components, resulting in a selection of components for a complete hybrid vehicle powertrain and aftertreatment system that is suitable for describing transients related to control of all-electric and hybrid diesel-/electric- drive in commercial vehicles. Another part is the system analysis, and optimal control results providing insights into the control of the system where engine-off time can be significant, and the heating and cooling become important for fuel economy and emissions. In Section 2.1 the contents of the papers are summarized and in Section 2.2 the most important scientific contributions are highlighted.

\subsection{Summary of the papers}

This section contains short summaries of the papers included in the thesis. Papers I to $\mathrm{V}$ contains models of components that are used to compile the complete vehicle model in Paper V. This model is then used in Paper VIII where a strategy that pre-heats the aftertreatment system before an engine-off event is developed. In Paper VI an energy management system for a long-haulage truck is developed and evaluated using an early version of the model in Paper V. Paper VII presents a strategy for optimal heating of the aftertreatment based on a simplified model of an engine and aftertreatment system. 


\section{Paper I: A Mean Value Model for Unsteady Gas Flows and Heat Transfer in Pipes}

by Olov Holmer and Lars Eriksson

By combining an adiabatic model of a control volume and that of a stationary one-dimensional flow with heat transfer with heat transfer in a pipe, a new model that is physically correct under certain conditions is developed. The resulting model is a quasi-dimensional lumped parameter mean value model. The model contains states for the temperature and pressure of the gas inside the pipe and the temperature of the pipe wall. The model is validated using both measurements from an engine in a test stand and simulations from a detailed one-dimensional model, with satisfactory agreement in both cases.

\section{Paper II: Selective Catalytic Reduction Catalyst Modeling for Control Purposes}

by Olov Holmer and Lars Eriksson

The focus in this paper is choosing a suitable model structure for a Selective Catalytic Reduction (SCR) Catalyst. The aim is to find, and implement, the most suitable model for control purposes in terms of accuracy and simulation time. By organizing the available models based on their structure and identifying the trends. It is shown that most models can be derived from a common set of equations describing the physics of the catalyst, and that two model structures are identified as candidates.

The two candidate models have a similar structure, and both divide the catalyst into a number of smaller identical segments but differ in the way the gas phase is handled. The first model describes the gas phase as a Continuously Stirred Tank Reactor (CSTR) resulting in dynamic states describing the temperature and concentrations inside the catalyst. The dynamics of these states describing the gas phase are fast compared to the other dynamics in the model, and therefore the second model assumes a quasi-static behavior of the gas phase. A consequence of quasi-static assumption of the gas phase is that the transport delay caused by the velocity of the gas is not present in the model. To remedy this a new way to include the transport delay is presented. The method is based on post-processing of the output from the model which can be done at a low computational cost.

The results show that the model based on the quasi-static behavior outperforms the model based on CSTR, when using a reasonable number of segments in the discretization (less than 40), both in accuracy and simulation time. It is also shown that around 20 segments in the discretization gives a good trade-off between simulation time and accuracy.

A tool for generating the models is also developed and presented. The tool 
is general and can be used to generate models of many types of catalyst and in particular a complete $\mathrm{NO}_{\mathrm{x}}$ reduction system can be modeled.

\title{
Paper III: A Simplified Diesel Particulate Filter Model
}

\author{
by Olov Holmer and Lars Eriksson
}

To describe filtering and soot buildup in a diesel particulate filter, fairly complex models are typically used. However, when focusing on $\mathrm{NO}_{\mathrm{x}}$ reduction the DPF plays a more passive role, making the extra complexity unnecessary. A simplified model is therefore developed by neglecting the soot buildup in the filter. The model is simplified further by assuming homogenous flow through the filter wall and that the gas acts as an incompressible fluid. The model is parameterized and validated against data produced by a high fidelity-model with satisfactory results.

\section{Paper IV: Modeling of Engine Aftertreatment System Cooling for Hybrid Vehicles}

by Olov Holmer, Fredrik Blomgren, and Lars Eriksson

Control oriented models of aftertreatment systems often describe the temperatures of the components in the aftertreatment system using a single thermal mass for each component, and sometimes a single thermal mass for the complete system. This approach will predict an exponential decay in temperature when the aftertreatment system is left to cooldown after the engine is turned off. Experimental data is used to show that this is not the case, and the work focuses on capturing the behavior of a cooling transient. The experimental data show temperature gradients in both the axial and radial dimensions. To capture this, a two-dimensional thermal model of a catalyst is developed. The model extends an existing one-dimensional model, describing the temperature gradient in the axial dimension, with the radial dimension. The radial dimension is included in two ways, one where the conduction in the substrate is calculated finite differences and one where it is calculated based on a Taylor expansion.

The model is compared with the experimental data, and it is shown that conduction both in the axial and radial dimension is needed to accurately describe cooling of the aftertreatment system. It is also investigated how many grid points in the discretization of the radial dimension that are needed, and it was shown that four grid points gave the best result when using finite differences. It was also shown that by using a Taylor expansion in the radial dimension the number of grid points in the radial dimension could be reduced to two, which reduces the number of states by half and speeds up the simulation time by around 14 


\section{Paper V: Modeling and Simulation of a Heavy-Duty Hybrid Electric Powertrain}

by Olov Holmer and Lars Eriksson

A model of a heavy-duty hybrid electric powertrain is developed by compiling submodels describing the components in the powertrain. To describe the internal combustion engine a map-based model, extended with a thermal mass describing the turbine, is used. The electric machine is also described using a map-based approach and the battery is modeled using a Thévenin equivalent circuit. The aftertreatment system is modeled using one-dimensional submodels of the catalysts and the diesel particulate filter. The model is validated using experimental data with satisfactory results when it comes to predicting the battery state of charge and tailpipe $\mathrm{NO}_{\mathrm{x}}$ emissions.

To simulate the model a method for solving ordinary differential methods is needed. These methods are usually iterative and require the differential equation to be continuous over the time span of each step for robust behavior. Since simulation of hybrid-powertrains often include discrete events like gear shifts and engine on/off events, this is of concern here. However, the differential equations describing the vehicle itself are continuous, and all discontinuities come from discontinuities in the inputs. Based on this observation, a method based on the Adams-Bashforth method is developed. The Adams-Bashforth method implicitly uses a prediction of the inputs when calculating the solution at the next step, and the difference between this predicted input and the actual input will induce an error in the solution. An estimation of this error is derived and using the bisection method the largest possible step that fulfill the error requirements can be calculated without evaluating the function describing the dynamics of the system. The method is compared with standard methods and the results show that the method is significantly faster at simulating problems with discontinuities in the inputs.

\section{Paper VI: Simultaneous Reduction of Fuel Consumption and $\mathrm{NO}_{\mathrm{x}}$ Emissions through Hybridization of a Long Haulage Truck}

by Olov Holmer and Lars Eriksson

Based on the equivalent consumption minimization strategy, where an equivalence factor is used to compare fuel and battery power so that an optimal distribution of power between the components in the powertrain can be calculated, an energy management system for a long haulage truck is developed. The proposed control system is evaluated in a driving scenario using a model of a complete hybrid electric truck, including an aftertreatment system, and the results are compared with a conventional, non-hybrid, vehicle. The results show $31 \%$ lower $\mathrm{NO}_{\mathrm{x}}$ emissions from the hybrid vehicle, primarily due to better thermal con- 
ditions in the exhaust system during braking, and at the same time, the fuel consumption was reduced by $3.8 \%$ compared to the non-hybrid vehicle. The conclusion is that, in addition to the expected reduction in fuel consumption, hybridization gives new capabilities to control the temperatures in the exhaust aftertreatment system, making it possible to increase its efficiency.

\section{Paper VII: Modeling and Analytical Solutions for Optimal Heating of Aftertreatment Systems}

by Olov Holmer and Lars Eriksson

A Hammerstein model of an engine and aftertreatment system and its analytical solutions for zero order hold control inputs are presented. Using the model, a control system based on numerical optimal control that heats the aftertreatment system to a specific temperature in an optimal way. A case study is performed on a Diesel engine and after treatment system where the results show that the solutions exhibit a structured and simple two-phase pattern. First there is a heating phase, where the catalyst is fed with a high temperature gas, building up a high inlet temperature. Then, in a second phase, the flow is kept high, and the temperature is pushed through the catalyst. It is also shown that the method is efficient numerically and solves the optimal catalyst heating problem 100-400 times faster than real time on a standard laptop of today.

To analyze the result a concept called heating enthalpy flow is defined as

$$
\dot{H}_{\text {heat }}=c_{p} W\left(T_{\text {gas }}-T_{\text {ref }}\right)
$$

where $c_{p}$ is the specific heat of the exhaust gas, $W$ is the exhaust mass flow, $T_{\text {gas }}$ is the temperature of the exhaust gas, and $T_{r e f}$ is a reference temperature. The background is that to heat the aftertreatment system to the temperature $T_{r e f}$ the input temperature must be above $T_{r e f}$ and the heating enthalpy flow can be seen as the enthalpy flow above this temperature. Heating enthalpy flow is therefore a way to illustrate the useful energy in the exhaust gas. Together with the two-phase behavior, this gives new insights that can be used, for example, when developing simpler rule-based control strategies.

\section{Paper VIII: Optimal Aftertreatment Pre-Heat Strategy for Minimum Tailpipe $\mathrm{NO}_{\mathrm{x}}$ Around Green Zones}

by Olov Holmer, Frank Willems, Fredrik Blomgren, and Lars Eriksson

A strategy that heats the aftertreatment before the engine is turned off in an optimal way to minimize $\mathrm{NO}_{\mathrm{x}}$ when the engine is restarted is developed. The strategy finds the optimal way to reduce $\mathrm{NO}_{\mathrm{x}}$ using a specified amount of fuel based on predictions from a model and an optimization scheme. The performance of the strategy is tested in simulations where a simplified scenario is used 
to evaluate under what conditions it is desirable to heat the aftertreatment system before turning off the engine. The results show that pre-heating of the aftertreatment system can be an effective strategy to reduce $\mathrm{NO}_{\mathrm{x}}$ for engine-off events shorter than two hours and is most effective for engine off events of around 1.5 hours. The results also show that for engine-off events longer than two hours, pre-heating quickly becomes an inefficient strategy. At this point, the ammonia storage when the engine is turned off is more important, and pre-heating can even make the results worse, since an increased SCR temperature results in lower ammonia storage before turning off the engine, which is detrimental for $\mathrm{NO}_{\mathrm{x}}$ conversion during the restart.

From this it can be concluded that ammonia storage and start of ammonia dosing after the engine-off event are important factors that affect how long engine-off times that pre-heating is an effective strategy. This also shows the importance of using a detailed model that include ammonia storage and temperature gradients in the SCR catalyst, since ammonia dosing is only allowed when the front of the catalyst has a sufficiently high temperature.

\section{Paper IX: Predictive Emission Management Based on Pre-Heating for Heavy-Duty Powertrains}

by Olov Holmer

An emission management strategy that, based on pre-heating of the aftertreament system, reduce the impact of a prolonged engine-off event on $\mathrm{NO}_{\mathrm{x}}$ emissions, is developed. The method locates each engine off event and handles each event separately using an optimization scheme and a combination of pre-heating and a causal heuristic emission management strategy. The individual events are linked using a common equivalence factor between fuel and $\mathrm{NO}_{\mathrm{x}}$ in the optimization of each event. The equivalence factor can be seen as a parameter to be chosen heuristically or iteratively to give a desired result.

The strategy is evaluated using simulations of a drive cycle with a single engine-off event of varying length, and a drayage cycle. The results from these simulations show that the strategy can reduce $\mathrm{NO}_{\mathrm{x}}$ compared to a baseline strategy, using the same amount of fuel, for engine-off times below $0.5 \mathrm{~h}$. If allowed using more fuel, the strategy can significantly reduce $\mathrm{NO}_{\mathrm{x}}$ for engineoff times up to $1.5 \mathrm{~h}$, after which an exponential decay in effectivity is observed. One of the main factors affecting the performance of the strategy is the time until ammonia dosing is allowed after the engine is restarted, and how time is reduced using pre-heating. The reduction in $\mathrm{NO}_{\mathrm{x}}$ is also shown to be fairly linear in the equivalence factor, which gives the process of choosing it a predictable behavior. 


\section{Other Publications by the Author}

- Olov Holmer and Lars Eriksson. "Modelling and Validation of Hybrid Heavy Duty Vehicles with Exhaust Aftertreatment Systems." In: Proceedings of the 58th Conference on Simulation and Modelling (SIMS 58) Reykjavik, Iceland, September 25th-27th, 2017. No. 138. Linköping University Electronic Press, 2017.

An early version of the model in Paper V used in Paper VI.

- Oskar Ljungqvist, Niclas Evestedt, Marcello Cirillo, Daniel Axehill, and Olov Holmer. "Lattice-based motion planning for a general 2-trailer system". In: 14th International Symposium on Advanced Vehicle Control 2017 IEEE Intelligent Vehicles Symposium (IV). IEEE, 2017.

\subsection{Scientific Contributions}

The contributions in the thesis are on modeling, system analysis, and control of engine/powertrain and aftertreatment systems in hybrid electric commercial vehicles.

The contributions to modeling are on modifications, extensions and implementations providing complete descriptions of how the models are implemented. The contributions also include how simulations are performed using efficient numerical methods. The contributions to this field are:

- A new compact control-oriented model for gas flows in pipes that captures flow dynamics with compression/expansion, wall heat transfer and mass transport in a thermodynamically consistent way.

- It is shown that most models for SCR catalysts can be derived from a common set of equations describing the physics of the catalyst. Two model structures are identified as the most common and are presented in detail and compared with each other.

- A way to include the transport delay of the gas in a catalyst using postprocessing of the outputs from a model that does not include the transport delay is presented.

- A simplified model of a diesel particulate filter is developed by neglecting the soot buildup in the filter.

- A tool for generating catalyst models is presented. The tool is general and can be used to generate models of many types of catalyst, in particular it can be used to model a complete $\mathrm{NO}_{\mathrm{x}}$ reduction system.

- Using models and experimental data it is shown that temperature gradients in both the axial and radial direction are important to describe the cooldown of an aftertreatment system.

- A numerical method for solving ordinary differential equations with discontinuities in the inputs is developed. The method is based on the Adams- 
Bashforth method and jointly locates the discontinuities and integrates the system.

- A Hammerstein model of an engine and aftertreatment system and its analytical solutions for zero order hold control inputs are presented. The model is used to develop an efficient method that finds the controls for heating the aftertreatment system to a specific temperature in an optimal way.

The contributions to control of combined powertrain and EATS systems for hybrid electric commercial vehicles are:

- It is shown that the optimal way to heat the aftertreatment system above a specific temperature exhibits a two-phase pattern. First there is a heating phase, where the catalyst is fed with a high temperature gas, building up a high inlet temperature. Then, in a second phase, the flow is kept high, and the temperature is pushed through the catalyst.

- A strategy that heats the aftertreatment before the engine is turned off in an optimal way to minimize $\mathrm{NO}_{\mathrm{x}}$ when the engine is restarted is developed.

- Based on the pre-heating strategy a predictive emission management strategy for reduced emissions from prolonged eninge-off events that can minimize $\mathrm{NO}_{\mathrm{x}}$ in drive cycles with multiple engine-off events is developed.

- It is shown that pre-heating of the aftertreatment system can be an effective strategy to reduce $\mathrm{NO}_{\mathrm{x}}$ for engine-off events shorter than two hours, and that it is most effective for engine off events of around 1.5 hours. Furthermore, for engine-off events longer than two hours, pre-heating is shown to become an inefficient strategy. The results also stress the importance of using a model of the aftertreatment system that includes ammonia storage and temperature gradients. 


\section{References}

[1] DieselNet. Emission standards - european union - heavy-duty truck and bus engines. www. dieselnet.com/standards/eu/hd.php. Accessed: 202001-10.

[2] The european green deal. Communication from the Commission to the European Parliament, the Council, the European Economic and Social Committee and the Committee of the Regions, 2019.

[3] Pathway to a healthy planet for all. Communication from the Commission to the European Parliament, the Council, the European Economic and Social Committee and the Committee of the Regions, 2021.

[4] G. Automotive and M. Industries. Development of post-euro 6/vi emission standards for cars, vans, lorries and buses. COMBINED EVALUATION ROADMAP / INCEPTION IMPACT ASSESSMENT, 2021.

[5] T. . Environment. Low-emission zones are a success - but they must now move to zero-emission mobility. www . transportenvironment.org/sites/te/ files/publications/2019_09_Briefing_LEZ-ZEZ_final.pdf. Accessed: 2020-01-10.

[6] R. Prohaska, A. Konan, K. Kelly, and M. Lammert. Heavy-duty vehicle port drayage drive cycle characterization and development. Technical report, National Renewable Energy Lab.(NREL), Golden, CO (United States), 2016.

[7] A. Sciarretta and L. Guzzella. Control of hybrid electric vehicles. IEEE Control Systems Magazine, 27(2):60-70, 2007.

[8] A. Brahma, Y. Guezennec, and G. Rizzoni. Optimal energy management in series hybrid electric vehicles. In American Control Conference, 2000. Proceedings of the 2000, volume 1. IEEE, 2000.

[9] G. Paganelli, T. Guerra, S. Delprat, J. Santin, M. Delhom, and E. Combes. Simulation and assessment of power control strategies for a parallel hybrid car. Proceedings of the Institution of Mechanical Engineers, Part D: Journal of Automobile Engineering, 214(7), 2000. 
[10] J. Ritzmann, G. Lins, and C. Onder. Optimization method for the energy and emissions management of a hybrid electric vehicle with an exhaust aftertreatment system. IFAC-PapersOnLine, 53(2):13797-13804, 2020.

[11] J. Kessels, F. Willems, W. Schoot, and P. Van Den Bosch. Integrated energy \& emission management for hybrid electric truck with scr aftertreatment. In 2010 IEEE Vehicle Power and Propulsion Conference, pages 1-6. IEEE, 2010.

[12] J. Kuchly, D. Nelson-Gruel, A. Charlet, Y. Chamaillard, and C. Nouillant. Projected gradient and model predictive control: Optimal energy and pollutants management for hybrid electric vehicle. IFAC-PapersOnLine, 52(5):121-127, 2019.

[13] J. Zhao and J. Wang. Model predictive control of integrated hybrid electric powertrains coupled with aftertreatment systems. In Dynamic systems and control conference, volume 46193, page V002T36A004. American Society of Mechanical Engineers, 2014.

[14] G. C. Koltsakis, Z. Samaras, A. Karvountzis-Kontakiotis, T. Zacharopoulou, and O. Haralampous. Implications of engine start-stop on after-treatment operation. SAE International Journal of Engines, 4(1):1571-1585, 2011.

[15] O. Holmer, F. Willems, F. Blomgren, and L. Eriksson. Optimal aftertreatment pre-heat strategy for minimum tailpipe nox around green zones. In 2020 WCX SAE World Congress Experience. SAE International, 2020.

[16] D. Biswas, S. Ghosh, S. Sengupta, and S. Mukhopadhyay. A predictive supervisory controller for an HEV operating in a zero emission zone. In 2019 IEEE Transportation Electrification Conference and Expo (ITEC), pages 1-6. IEEE, 2019.

[17] J. Soldo, B. Skugor, and J. Deur. Optimal energy management control of a parallel plug-in hybrid electric vehicle in the presence of low emission zones. $S A E$ Technical Paper 2019-01-1215, 2019.

[18] L. Serrao, A. Sciarretta, O. Grondin, A. Chasse, Y. Creff, D. Di Domenico, P. Pognant-Gros, C. Querel, and L. Thibault. Open issues in supervisory control of hybrid electric vehicles: A unified approach using optimal control methods. Oil \& Gas Science and Technology-Revue d'IFP Energies nouvelles, 68(1):23-33, 2013.

[19] D. Kum, H. Peng, and N. K. Bucknor. Supervisory control of parallel hybrid electric vehicles for fuel and emission reduction. Journal of dynamic systems, measurement, and control, 133(6):061010, 2011.

[20] F. Willems, S. Spronkmans, and J. Kessels. Integrated powertrain control to meet low $\mathrm{CO} 2$ emissions for a hybrid distribution truck with SCR-DeNOx system. In ASME 2011 Dynamic Systems and Control Conference and Bath/ASME Symposium on Fluid Power and Motion Control, pages 907-912. American Society of Mechanical Engineers Digital Collection, 2011. 
Papers 



\section{Papers}

The papers associated with this thesis have been removed for copyright reasons. For more details about these see:

https://doi.org/10.3384/9789179291921 


\section{Dissertations \\ Division of Vehicular Systems \\ Department of Electrical Engineering \\ Linköping University}

No. 1 Magnus Pettersson, Driveline Modeling and Control, 1997.

No. 2 Lars Eriksson, Spark Advance Modeling and Control, 1999.

No. 3 Mattias Nyberg, Model Based Fault Diagnosis: Methods, Theory, and Automotive Engine Applications, 1999.

No. 4 Erik Frisk, Residual Generation for Fault Diagnosis, 2001.

No. 5 Per Andersson, Air Charge Estimation in Turbocharged Spark Ignition Engines, 2005.

No. 6 Mattias Krysander, Design and Analysis of Diagnosis Systems Using Structural Methods, 2006.

No. 7 Jonas Biteus, Fault Isolation in Distributed Embedded Systems, 2007.

No. 8 Ylva Nilsson, Modelling for Fuel Optimal Control of a Variable Compression Engine, 2007.

No. 9 Markus Klein, Single-Zone Cylinder Pressure Modeling and Estimation for Heat Release Analysis of SI Engines, 2007.

No. 10 Anders Fröberg, Efficient Simulation and Optimal Control for Vehicle Propulsion, 2008.

No.11 Per Öberg, A DAE Formulation for Multi-Zone Thermodynamic Models and its Application to CVCP Engines, 2009.

No. 12 Johan Wahlström, Control of EGR and VGT for Emission Control and Pumping Work Minimization in Diesel Engines, 2009.

No. 13 Anna Pernestål, Probabilistic Fault Diagnosis with Automotive Applications, 2009.

No. 14 Erik Hellström, Look-ahead Control of Heavy Vehicles, 2010.

No. 15 Erik Höckerdal, Model Error Compensation in ODE and DAE Estimators with Automotive Engine Applications, 2011.

No. 16 Carl Svärd, Methods for Automated Design of Fault Detection and Isolation Systems with Automotive Applications, 2012.

No. 17 Oskar Leufvén, Modeling for Control of Centrifugal Compressors,

No. 18 Christofer Sundström, Model Based Vehicle Level Diagnosis for Hybrid Electric Vehicles, 2014.

No. 19 Andreas Thomasson, Modeling and control of actuators and cosurge in turbocharged engines, 2014.

No. 20 Emil Larsson, Model Based Diagnosis and Supervision of Industrial Gas Turbines, 2014.

No. 21 Andreas Myklebust, Dry Clutch Modeling, Estimation, and Control, 2014.

No. 22 Tomas Nilsson, Optimal Engine Operation in a Multi-Mode CVT Wheel Loader, 2015. 
No. 23 Daniel Jung, Diagnosability Performance Analysis of Models and Fault Detectors, 2015.

No. 24 Martin Sivertsson, Optimal Control of Electrified Powertrains, 2015.

No. 25 Peter Nyberg, Evaluation, Generation, and Transformation of Driving Cycles, 2015.

No. 26 Kristoffer Lundahl, Models and Critical Maneuvers for Road Vehicles, 2016.

No. 27 Vaheed Nezhadali, Modeling and Optimal Control of Heavy-duty Powertrains, 2016.

No. 28 Xavier Llamas, Modeling and Control of EGR on Marine TwoStroke Diesel Engines, 2018.

No. 29 Sergii Voronov, Machine Learning for Predictive Maintenance, 2020.

No. 30 Victor Fors, Autonomous Vehicle Maneuvering at the Limit of friction, 2020.

No. 31 Fatemeh Mohseni, Decentralized Optimal Control for Multiple Autonomous Vehicles in Traffic Scenarios, 2021.

No. 32 Mahdi Morsali, Trajectory Planning for an Autonomous Vehicle in Multi-Vehicle Traffic Scenarios, 2021.

No. 33 Kristoffer Ekberg, Modeling and Optimal Control for Dynamic Driving of Hybridized Vehicles with Turbocharged Diesel Engines, 2021.

No. 34 Pavel Anistratov, Autonomous Avoidance Maneuvers for Vehicles Using Optimization, 2021.

No. 35 Iman Shafikhani, Energy Management Strategy Design for Series Hybrid Electric Vehicles, 2021.

No. 36 Robin Holmbom, Modeling and Model-based Control of Automotive Air Paths, 2022. 


\section{FACULTY OF SCIENCE AND ENGINEERING}

Linköping Studies in Science and Technology, Dissertation No. 2204, 2022 Department of Electrical Engineering

Linköping University

SE-581 83 Linköping, Sweden

www.liu.se 